\title{
Morphological Characterization of Sorghum [Sorghum bicolor (L.) Moench] Germplasm for DUS Traits
}

\author{
Deepak Raj Prajapati*, S.K. Pahuja, N.K. Verma and Shalu Chaudhary \\ Department of Genetics and Plant Breeding, Chaudhary Charan Singh Haryana Agriculture \\ University, Hisar, India \\ *Corresponding author
}

\section{A B S T R A C T}

Keywords

Sorghum,

Morphological DUS

descriptors,

Indigenous cultivar

Article Info

Accepted:

17 January 2018

Available Online:

10 February 2018
A total of 75 sorghum germplasm lines including 74 Indigenous cultivar (IC) and one Exotic cultivar (EC) were characterized using 27 morphological descriptors provided by PPV \& FRA for DUS testing in sorghum. Results revealed that maximum variation was present among genotypes for glume traits viz., colour (6 groups), neck of panicle (5 groups), length for flower with pedicel (5 groups), time of panicle emergence (4 groups), colour of dry anther (4 groups), panicle length of branches (4 groups), panicle shape (4 groups) and caryopsis colour (4 groups). Classification of genotypes on the basis of DUS traits provided identification of key characteristics of various genotypes.

\section{Introduction}

Sorghum [Sorghum bicolour (L.) Moench] is in the fifth position among cereal crop globally after wheat (Triticum aestivum), rice (Oryza sativa), maize (Zea mays) and barley (Hordeum vulgare). It is the very important dry land cereal crop for the semi-arid tropics. It is relative tolerant to drought and heat makes it an ideal crop for human being and animal consumption in areas with extreme unfavorable temperatures and in dry regions receiving minimum precipitation (Ratnavathi et al., 2012). Several single cut, multi cut and dual purpose varieties have been released time to time for cultivation in diverse climatic regions of India. Still yield and quality needed to improve to meet growing demand and this is possible only by utilizing existing genetic variability.

The basic material utilized in finding genetic variability is germplasm. Germplasm is defined as the total gene pool of a species consisting of landraces, advanced breeding lines, popular cultivars, wild and weedy relatives (Upadhyaya et al., 2010). Sorghum is supposed to have a wide range of diverse germplasm. Plant genetic resources play an important role in generating new crop 
varieties with high yield and desired traits. Various research methodologies are employed in in-situ and ex-situ conservation of genetic diversity in plants (Shehzad et al., 2014).

Morphological markers are based on traits which can be visually assessed such as flower color, seed shape, growth habits and pigmentation, and such markers do not require expensive technology. Collection of existing germplasm and their characterization is a prerequisite for identifying important genotypes for improvement of varieties and to avoid repetition in the germplasm collection. Morphological, biochemical and molecular markers have been deployed in characterization of crop genetic resources. Among these, morphological characterization of germplasm is the easiest and cheapest method of classification, estimating diversity and registering cultivar (Dossou-Aminon et al., 2015).

To test for distinctness, uniformity and stability DUS Testing is one of the important criteria. It provides a detailed description of accessions which can be used for protection and identification of plant verities. Sorghum is one among the first set of 12 crop species notified by Govt. of India for registration under the Protection of Plant Varieties and Farmers' Rights Act, 2001 (PPVandFRA, 2007a).

Therefore, the present investigation was undertaken with objective to characterize Sorghum germplasm Morphologically for DUS traits.

\section{Materials and Methods}

The experimental material consists of 75 sorghum germplasm accessions. The trial was conducted during kharif season of 2015-16. The experiment was planted in a randomized block design with three replications. The total of 27 characters was selected for the characterization of the germplasm on the basis of DUS guidelines. The accessions were collected from the genetics and plant breeding department CCSHAU, Hisar. The lines were grown in the 3 meter length with $45 \mathrm{~cm}$ (row to row) and the $15 \mathrm{~cm}$ (plant to plant) distance. The accession used for the present study is listed in Table 1.

The data was taken on the basis of DUS guidelines for Sorghum Distinctiveness for the traits were also checked for the all the genotypes. The descriptors and the time and way of taking data are described in Table 2.

Grouping of sorghum germplasm was done by utilizing grouping characteristics which mentioned in the DUS test guidelines of PPV and FR Authority for sorghum.

\section{Results and Discussion}

The DUS descriptors for any plant variety are very important with purpose of rights over plant verities and their protection from unauthorized person. The data was collected on the basis of the DUS guidelines for sorghum was found that all the genotypes were distinctive with each other and have got different characteristics. These characteristics are useful to establish distinctiveness, uniformity and stability of a variety, based on which the variety is given protection. The genotypes were classified into distinctive classes on the basis of guidelines. Therefore, there is a great need to characterize genotypes to identify varietal purity, Protection of Plant Variety and Farmers' Right.

\section{Seedling stage}

Sorghum seedling anthocyanin colouraion of coleoptiles was examined at seedling stage for their characterization. Based on the variation observed in this character, it was possible to 
distinguish all genotypes broadly into two categories: yellow green (15) and grayed purple (60 genotypes). Nagaraja et al., (2000), Selvaraju et al., (2000) and Raghuvanshi et al., (2014) also studied similar traits.

\section{$5^{\text {th }}$ leaf stage}

At $5^{\text {th }}$ leaf stage genotypes were characterized on the basis of two characters, leaf sheath anthocyanin colouration and leaf midrib colour of $5^{\text {th }}$ fully developed leaf. All genotypes exhibited similar colouration pattern as was observed in case of seedling anthocyanin colouration of coleoptiles except one. Genotype IC-484437 had anthocynin colouration at seedling stage but it was observed that it was absent at $5^{\text {th }}$ leaf stage. Fifty nine genotypes had yellow green and 16 had grayed purple. On the basis of leaf midrib colour the genotypes were categorized into two groups: white (47 genotypes) and yellow green (28 genotypes). These results are in accordance with those of Sangwan et al., (2005), Elangovan et al., (2007), Reddy et al., (2008), Habindavyi (2009), Raghuvanshi et al., (2014).

\section{Panicle emergence stage}

Genotypes were characterized on the basis of time of panicle emergence (50\% of plants with $50 \%$ flowering), natural height of plant up to the base of flag leaf and flag leaf yellow colouration of midrib at panicle emergence stage. Genotypes were grouped into four categories viz., early (5 genotypes), medium (5 genotypes), late ( 7 genotypes) and very late (58 genotypes) for time of panicle emergence, whereas, genotypes were divided into two groups i.e. very short (6 genotypes), short (64 genotypes) and medium (5 genotypes) on the basis of plant height up to the base of flag leaf and 23 genotypes exhibited yellow colouration of midrib while 52 genotypes were without yellow colouration in midrib of flag leaf. These results are in accordance with those of Reddy et al., (2008), Reddy et al., (20090, Kannababu et al., (2013) and Raghuvanshi et al., (2014).

\section{Flowering stage}

Sorghum genotypes were classified into different groups based on lemma arista formation, stigma anthocyanin colouration, stigma yellow colouration, anther length, stigma length, colour of dry anther and flower with pedicel length of flower. Based on the lemma arista formation observed on this character, it was possible to distinguish all genotypes broadly into two categories: lemma arista present (20 genotypes) and absent (55 genotypes). Based on colour of dry anther, genotypes were classified into four categories viz., yellow orange (26 genotypes), orange (33 genotypes) red orange (10 genotypes) and grayed orange (6 genotypes) while, on the basis of length for flower with pedicel length of flower, genotypes were also divided into five groups very short (5 genotypes), short (4 genotypes), medium (17 genotypes), long (39 genotypes) and very long (10 genotypes). However, on the basis of stigma yellow colouration and stigma anthocyanin colouration, genotypes were divided into two groups i.e. absent (49 and 6 genotypes) and present (26 and 69 genotypes), respectively. In case of stigma length genotypes fell under short (6 genotypes), medium (50 genotypes) and long (19 genotypes) stigma length. On the basis of anther length genotypes were divided into three categories viz., short (18 genotypes), medium (53 genotypes) and long (4 genotypes). These results are in accordance with those of Kolberg (1999), Reddy et al., (2006), Reddy et al., (2009) and Joshi et al., (2009).

\section{Physiological maturity}

Characters like, glume colour, panicle length of branches, panicle density at maturity, panicle shape, neck of panicle visible above 
sheath, glume length and grain threshability were recorded for characterization of genotypes at physiological maturity. On the basis of glume colour genotypes were categorized into six groups viz., green white (16 genotypes), yellow white (2 genotypes), grayed yellow (7 genotypes), grayed orange (5 genotypes), grayed red (6 genotypes), grayed purple (39 genotypes). However, on the basis of neck of panicle visible above sheath genotypes were also divided into five groups namely, very short (12 genotypes), short (11 genotypes), medium (33 genotypes), long (14 genotypes), very long (5 genotypes). Whereas, on the basis of panicle density at maturity genotypes could be divided into five categories viz., very loose (IC-253535), loose (3 genotypes), semi loose (38 genotypes), semi compact (27 genotypes), compact (6 genotypes). Genotypes could be divided into four groups viz., short (9 genotypes), medium
(23 genotypes), long (10 genotypes) and very long (33 genotype) on the basis of glume length. Genotypes were characterized into four groups viz., short (34 genotypes), medium (40 forty genotypes) and long (1 genotype) on the basis of panicle length of branches. In case of panicle shape genotypes were characterized into four groups viz., panicle broader in upper part (1 genotype), symmetrical (18 genotypes), panicle broader in lower part (15 genotypes) and pyramidal in their panicle shape (41 genotypes). Genotypes were classified on the basis of threshability in three categories viz., freely threshable (27 genotypes), partly threshable (12 genotypes) and difficult to thresh (36 genotypes). These traits are also studied and found diverse by Pahuja et al., (2002), Umakanth et al., (2002) , Sangwan et al., (2005), Elangovan et al., (2006), Nabi et al., (2006), Reddy et al., (2009) and Missihoun et al., (2015).

Table.1 List of Accession used for study

\begin{tabular}{|l|l|l|l|l|l|l|l|}
\hline $\mathbf{S} \mathbf{5} \mathbf{N o}$ & $\begin{array}{l}\text { Accession } \\
\text { number }\end{array}$ & Sr. No. & $\begin{array}{l}\text { Accession } \\
\text { number }\end{array}$ & Sr. No. & $\begin{array}{l}\text { Accession } \\
\text { number }\end{array}$ & $\begin{array}{l}\text { Sr. No. } \\
\text { Accession } \\
\text { number }\end{array}$ \\
\hline $\mathbf{1}$ & IC-485120 & 21 & IC-485237 & 41 & IC-484542 & 61 & IC-484949 \\
\hline $\mathbf{2}$ & IC-485121 & 22 & IC-485242 & 42 & IC-484588 & 62 & IC-484951 \\
\hline $\mathbf{3}$ & IC-485251 & 23 & EC-524468 & 43 & IC-484623 & 63 & IC-485054 \\
\hline $\mathbf{4}$ & IC-484363 & 24 & IC-253535 & 44 & IC-484640 & 64 & IC-485099 \\
\hline $\mathbf{5}$ & IC-484374 & 25 & IC-289225 & 45 & IC-484643 & 65 & IC-485115 \\
\hline $\mathbf{6}$ & IC-484410 & 26 & IC-484369 & 46 & IC-484684 & 66 & IC-485124 \\
\hline $\mathbf{7}$ & IC-484438 & 27 & IC-484437 & 47 & IC-485170 & 67 & IC587848 \\
\hline $\mathbf{8}$ & IC-484448 & 28 & IC-484475 & 48 & IC-485223 & 68 & IC-587849 \\
\hline $\mathbf{9}$ & IC-484471 & 29 & IC-484503 & 49 & IC-484364 & 69 & IC-587850 \\
\hline $\mathbf{1 0}$ & IC-484547 & 30 & IC-484522 & 50 & IC-484537 & 70 & IC-587852 \\
\hline $\mathbf{1 1}$ & IC-484559 & 31 & IC-484526 & 51 & IC-484546 & 71 & IC-587855 \\
\hline $\mathbf{1 2}$ & IC-484606 & 32 & IC-484675 & 52 & IC-484587 & 72 & IC-587856 \\
\hline $\mathbf{1 3}$ & IC-484621 & 33 & IC-484685 & 53 & IC-484622 & 73 & IC-587857 \\
\hline $\mathbf{1 4}$ & IC-484657 & 34 & IC-484794 & 54 & IC-484674 & 74 & IC-587858 \\
\hline $\mathbf{1 5}$ & IC-484678 & 35 & IC-485072 & 55 & IC-484739 & 75 & IC-587859 \\
\hline $\mathbf{1 6}$ & IC-484875 & 36 & IC-485100 & 56 & IC-484757 & & \\
\hline $\mathbf{1 7}$ & IC-485113 & 37 & IC-485231 & 57 & IC-484777 & & \\
\hline $\mathbf{1 8}$ & IC-485119 & 38 & IC-484365 & 58 & IC-484779 & & \\
\hline $\mathbf{1 9}$ & IC-485132 & 39 & IC-484390 & 59 & IC-484889 & & \\
\hline $\mathbf{2 0}$ & IC-485160 & 40 & IC-484483 & 60 & IC-484920 & & \\
\hline
\end{tabular}


Table.2 Descriptors used to characterize the present geneotypes

\begin{tabular}{|c|c|c|c|}
\hline & Parameters & States & Stage of observation \\
\hline 2.1 & $\begin{array}{l}\text { Seedling anthocyanin colouration } \\
\text { of coleoptiles }\end{array}$ & $\begin{array}{l}\text { yellow green } \\
\text { grayed purple }\end{array}$ & $\begin{array}{l}\text { Seedling } \\
7-8 \text { days after sowing }\end{array}$ \\
\hline 2.2 & $\begin{array}{l}\text { Leaf sheath anthocyanin } \\
\text { Colouration }\end{array}$ & $\begin{array}{l}\text { yellow green } \\
\text { grayed purple }\end{array}$ & 5th leaf \\
\hline 2.3 & $\begin{array}{l}\text { Leaf mid rib colour } \\
\text { ( } 5 \text { th fully developed leaf) }\end{array}$ & $\begin{array}{l}\text { white } \\
\text { yellow green } \\
\text { grayed yellow } \\
\text { grayed purple }\end{array}$ & 5th leaf \\
\hline 2.4 & $\begin{array}{l}\text { Time of panicle emergence } \\
(50 \% \text { of the plants with } 50 \% \text { anthesis) }\end{array}$ & $\begin{array}{l}\text { very early ( }<56 \text { days }) \\
\text { early ( } 56-65 \text { days) } \\
\text { medium ( } 66-75 \text { days }) \\
\text { late }(76-85 \text { days }) \\
\text { very late }(>85 \text { days })\end{array}$ & Panicle emergence \\
\hline 2.5 & Plant height up to base of flag leaf & $\begin{array}{l}\text { very short }(<76 \mathrm{~cm}) \\
\text { short }(76-150 \mathrm{~cm}) \\
\text { medium }(151-225 \mathrm{~cm}) \\
\text { tall }(226-300 \mathrm{~cm}) \\
\text { very tall }(>300 \mathrm{~cm})\end{array}$ & Panicle emergence \\
\hline 2.6 & Flag leaf yellow colouration of Midrib & $\begin{array}{l}\text { absent } \\
\text { present }\end{array}$ & Panicle emergence \\
\hline 2.7 & Lemma arista formation & $\begin{array}{l}\text { absent } \\
\text { present }\end{array}$ & Flowering \\
\hline 2.8 & Stigma anthocyanin colouration & $\begin{array}{l}\text { absent } \\
\text { present }\end{array}$ & $\begin{array}{l}\text { Upper portion of the } \\
\text { panicle at the end of } \\
\text { flowering }\end{array}$ \\
\hline 2.9 & Stigma yellow colouration & $\begin{array}{l}\text { absent } \\
\text { present }\end{array}$ & Flowering \\
\hline 2.10 & Stigma length & $\begin{array}{l}\text { short }(<1 \mathrm{~mm}) \\
\text { medium }(1-2 \mathrm{~mm}) \\
\text { long }(>2 \mathrm{~mm})\end{array}$ & Flowering \\
\hline 2.11 & Flower with pedicel: length of Flower & $\begin{array}{l}\text { very short } \\
\text { short } \\
\text { medium } \\
\text { long } \\
\text { very long }\end{array}$ & Flowering \\
\hline 2.12 & Anther length & $\begin{array}{l}\text { short }(<3 \mathrm{~mm}) \\
\text { medium }(3-4 \mathrm{~mm}) \\
\text { long }(>4 \mathrm{~mm})\end{array}$ & Flowering \\
\hline 2.13 & Anther colour of dry anther & $\begin{array}{l}\text { yellow orange } \\
\text { orange } \\
\text { orange red } \\
\text { grayed orange }\end{array}$ & End of flowering \\
\hline 2.14 & Glume colour & $\begin{array}{l}\text { green white } \\
\text { yellow white } \\
\text { grayed yellow } \\
\text { grayed orange } \\
\text { grayed red } \\
\text { grayed purple }\end{array}$ & $\begin{array}{l}\text { Physiological maturity of } \\
\text { grain }\end{array}$ \\
\hline 2.15 & $\begin{array}{l}\text { Panicle length of branches } \\
\text { (middle third of panicle) }\end{array}$ & $\begin{array}{l}\text { short }(<5.1 \mathrm{~cm}) \\
\text { medium }(5.1-10 \mathrm{~cm}) \\
\text { long }(10.1-15 \mathrm{~cm}) \\
\text { very long }(>15 \mathrm{~cm})\end{array}$ & Physiological maturity \\
\hline 2.16 & $\begin{array}{l}\text { Panicle density at maturity } \\
\text { (ear head compactness) }\end{array}$ & $\begin{array}{l}\text { very loose } \\
\text { loose } \\
\text { semi loose } \\
\text { semi compact } \\
\text { compact }\end{array}$ & Physiological maturity \\
\hline
\end{tabular}




\begin{tabular}{|c|c|c|c|}
\hline 2.17 & Panicle shape & $\begin{array}{l}\text { reversed pyramid } \\
\text { panicle broader in } \\
\text { upper part } \\
\text { symmetric } \\
\text { panicle broader in } \\
\text { lower part } \\
\text { pyramidal }\end{array}$ & Physiological maturity \\
\hline 2.18 & Neck of panicle visible length above sheath & $\begin{array}{l}\text { absent or very short } \\
(<5.1 \mathrm{~cm}) \\
\text { short }(5.1-10 \mathrm{~cm}) \\
\text { medium }(10.1-15 \mathrm{~cm}) \\
\text { long }(15.1-20 \mathrm{~cm}) \\
\text { very long }(>20 \mathrm{~cm})\end{array}$ & Physiological maturity \\
\hline 2.19 & Glume length & $\begin{array}{l}\text { very short ( } 25 \% \text { of } \\
\text { grain covered) } \\
\text { short }(50 \% \text { of grain covered }) \\
\text { medium }(75 \% \text { of } \\
\text { grain covered) } \\
\text { long ( } 100 \% \text { of grain covered) } \\
\text { very long (longer } \\
\text { than the grain) }\end{array}$ & Physiological maturity \\
\hline 2.20 & Grain Threshability & $\begin{array}{l}\text { freely threshable } \\
\text { ( }<11 \% \text { unthreshed grain) } \\
\text { partly thresahble } \\
(11-50 \% \\
\text { unthreshed grain) } \\
\text { difficult to thresh } \\
\text { (>50\% unthreshed } \\
\text { grain) }\end{array}$ & Maturity \\
\hline 2.21 & Caryopsis colour after threshing & $\begin{array}{l}\text { white RHS } 155 \\
\text { grayed white RHS156 } \\
\text { yellow white RHS158 } \\
\text { yellow orange RHS14-20 } \\
\text { grayed orange RHS200 }\end{array}$ & After threshing \\
\hline 2.22 & Grain: shape (in dorsal view) & $\begin{array}{l}\text { narrow elliptic } \\
\text { elliptic } \\
\text { circular }\end{array}$ & After threshing \\
\hline 2.23 & Grain shape in profile view & $\begin{array}{l}\text { narrow elliptic } \\
\text { elliptic } \\
\text { circular }\end{array}$ & After threshing \\
\hline 2.24 & Grain size of mark of germ & $\begin{array}{l}\text { very small } \\
\text { small } \\
\text { medium } \\
\text { large } \\
\text { very large }\end{array}$ & After threshing \\
\hline 2.25 & $\begin{array}{l}\text { Grain texture of endosperm (in longitudinal } \\
\text { section) }\end{array}$ & $\begin{array}{l}\text { fully vitreous ( } 100 \% \text { corneous) } \\
\text { vitreous }(75 \% \text { corneous) } \\
\text { half vitreous }(50 \% \text { corneous }) \\
\text { farinaceous }(25 \% \text { corneous }) \\
\text { fully farinaceous }(0 \% \text { corneous) }\end{array}$ & After threshing \\
\hline 2.26 & Grain colour of vitreous albumen & $\begin{array}{l}\text { grayed yellow RHS160-162 } \\
\text { grayed orange RHS166 } \\
\text { grayed purple RHSN187 }\end{array}$ & After threshing \\
\hline 2.27 & Grain luster & $\begin{array}{l}\text { non-lustrous } \\
\text { lustrous }\end{array}$ & After threshing \\
\hline
\end{tabular}


Int.J.Curr.Microbiol.App.Sci (2018) 7(2): 2058-2071

\begin{tabular}{|c|c|c|c|c|c|c|c|c|c|c|c|c|c|}
\hline Line & $\begin{array}{c}\text { Seedling } \\
\text { anthocynin }\end{array}$ & $\begin{array}{c}\text { Leaf sheath } \\
\text { anthocyanin } \\
\text { colouration }\end{array}$ & $\begin{array}{l}\text { Leaf mid rib } \\
\text { colour }\end{array}$ & $\begin{array}{l}\text { Days to panicle } \\
\text { emergence }\end{array}$ & $\begin{array}{c}\text { Height of the } \\
\text { plant up to the } \\
\text { base of flag leaf }\end{array}$ & $\begin{array}{c}\text { Flag leaf yellow } \\
\text { colouration of } \\
\text { mid rib }\end{array}$ & $\begin{array}{l}\text { Lemma arista } \\
\text { formation }\end{array}$ & $\begin{array}{c}\text { Stigma } \\
\text { anthocyanin } \\
\text { colouration }\end{array}$ & $\begin{array}{l}\text { Stigma yellow } \\
\text { colouration }\end{array}$ & Stigma Length & $\begin{array}{l}\text { Flower with pedicel: } \\
\text { length of flower }\end{array}$ & Anther length & $\begin{array}{l}\text { Anther colour } \\
\text { of dry anther }\end{array}$ \\
\hline IC-485120 & Absent & Absent & $\begin{array}{l}\text { Yellow } \\
\text { Green }\end{array}$ & Very late & Short & Present & Absent & Absent & Absent & Medium & Medium & Long & $\begin{array}{l}\text { Yellow } \\
\text { orange }\end{array}$ \\
\hline IC-485121 & Absent & Absent & $\begin{array}{l}\text { Yellow } \\
\text { Green }\end{array}$ & Very late & Short & Present & Absent & Present & Absent & Medium & Medium & Medium & Orange \\
\hline IC-485251 & Absent & Absent & White & Very late & Short & Absent & Absent & Present & Absent & Medium & Medium & Medium & Orange \\
\hline IC-484363 & Present & Present & $\begin{array}{l}\text { Yellow } \\
\text { Green }\end{array}$ & Very late & Short & Absent & Absent & Present & Present & Medium & Long & Medium & Orange \\
\hline IC-484374 & Present & Present & White & Very late & Short & Absent & Absent & Present & Present & Medium & Long & Medium & Orange \\
\hline IC-484410 & Present & Present & White & Very late & Short & Absent & Absent & Present & Absent & Medium & Long & Medium & $\begin{array}{l}\text { Yellow } \\
\text { orange }\end{array}$ \\
\hline IC-484438 & Present & Present & White & Very late & Short & Absent & Absent & Absent & Absent & Medium & Medium & Medium & $\begin{array}{l}\text { Yellow } \\
\text { orange }\end{array}$ \\
\hline IC-484448 & Present & Present & White & Very late & Short & Absent & Present & Present & Present & Long & Long & Medium & $\begin{array}{l}\text { Yellow } \\
\text { orange }\end{array}$ \\
\hline IC-484471 & Absent & Absent & $\begin{array}{l}\text { Yellow } \\
\text { Green }\end{array}$ & Late & Very Short & Absent & Absent & Present & Absent & Medium & Medium & Short & Red orange \\
\hline IC-484547 & Present & Present & White & Very late & Short & Absent & Absent & Present & Present & Medium & Medium & Medium & $\begin{array}{l}\text { Yellow } \\
\text { orange }\end{array}$ \\
\hline IC-484559 & Present & Present & White & Very late & Short & Absent & Absent & Present & Absent & Medium & Medium & Medium & Orange \\
\hline IC-484606 & Present & Present & $\begin{array}{l}\text { Yellow } \\
\text { Green }\end{array}$ & Late & Medium & Absent & Present & Present & Absent & Long & Long & Medium & Orange \\
\hline IC-484621 & Present & Present & $\begin{array}{l}\text { Yellow } \\
\text { Green }\end{array}$ & Medium & Short & Absent & Absent & Present & Absent & Very Short & Long & $\begin{array}{l}\text { Mediumediu } \\
\text { Medium }\end{array}$ & $\begin{array}{l}\text { Yellow } \\
\text { orange }\end{array}$ \\
\hline IC-484657 & Present & Present & White & Very late & Short & Absent & Present & Present & Absent & Long & Long & Long & Orange \\
\hline IC-484678 & Absent & Absent & $\begin{array}{l}\text { Yellow } \\
\text { Green }\end{array}$ & Very late & Short & Present & Absent & Present & Absent & Long & Long & Medium & $\begin{array}{l}\text { Yellow } \\
\text { orange }\end{array}$ \\
\hline IC-484875 & Present & Present & White & Very late & Short & Absent & Absent & Present & Present & Medium & Long & Medium & $\begin{array}{l}\text { Yellow } \\
\text { orange }\end{array}$ \\
\hline IC-485113 & Present & Present & White & Early & Short & Absent & Absent & Present & Present & Medium & Very Long & Medium & Orange \\
\hline IC-485119 & Present & Present & White & Medium & Short & Absent & Absent & Present & Present & Medium & Long & Medium & $\begin{array}{l}\text { Yellow } \\
\text { orange }\end{array}$ \\
\hline IC-485132 & Present & Present & White & Early & Short & Absent & Present & Present & Present & Medium & Long & Medium & Red orange \\
\hline IC-485160 & Absent & Absent & $\begin{array}{l}\text { Yellow } \\
\text { Green }\end{array}$ & Very late & Very Short & Absent & Absent & Present & Absent & Long & Medium & Medium & $\begin{array}{l}\text { Yellow } \\
\text { orange }\end{array}$ \\
\hline IC-485237 & Present & Present & White & Very late & Short & Present & Present & Present & Absent & Long & Long & Medium & $\begin{array}{l}\text { Yellow } \\
\text { orange }\end{array}$ \\
\hline IC-485242 & Present & Present & White & Very late & Short & Absent & Absent & Present & Present & Medium & Long & Medium & $\begin{array}{l}\text { Greyed } \\
\text { orange }\end{array}$ \\
\hline EC-524468 & Absent & Absent & White & Very late & Short & Absent & Present & Present & Present & Long & Very long & Medium & $\begin{array}{l}\text { Yellow } \\
\text { orange }\end{array}$ \\
\hline IC-253535 & Present & Present & White & Late & Medium & Absent & Absent & Present & Present & Medium & Medium & Short & Red orange \\
\hline IC-289225 & Present & Present & White & Early & Short & Absent & Absent & Present & Absent & Medium & Very long & Short & $\begin{array}{l}\text { Greyed } \\
\text { orange }\end{array}$ \\
\hline IC-484369 & Present & Present & $\begin{array}{l}\text { Yellow } \\
\text { Green }\end{array}$ & Very late & Short & Absent & Absent & Present & Absent & Medium & Long & Short & Orange \\
\hline
\end{tabular}


Int.J.Curr.Microbiol.App.Sci (2018) 7(2): 2058-2071

\begin{tabular}{|c|c|c|c|c|c|c|c|c|c|c|c|c|c|}
\hline IC-484437 & Present & Absent & $\begin{array}{l}\text { Yellow } \\
\text { Green }\end{array}$ & Very late & Short & Absent & Present & Absent & Absent & Long & Long & Medium & $\begin{array}{l}\text { Yellow } \\
\text { orange }\end{array}$ \\
\hline IC-484475 & Absent & Absent & $\begin{array}{l}\text { Yellow } \\
\text { Green }\end{array}$ & Early & Very Short & Present & Present & Present & Present & Long & Very long & Medium & Orange \\
\hline IC-484503 & Absent & Absent & $\begin{array}{l}\text { Yellow } \\
\text { Green }\end{array}$ & Very late & Very Short & Present & Absent & Present & Absent & Medium & Long & Short & Orange \\
\hline IC-484522 & Absent & Absent & $\begin{array}{l}\text { Yellow } \\
\text { Green }\end{array}$ & Very late & Very Short & Present & Absent & Present & Absent & Very Short & Medium & Medium & $\begin{array}{l}\text { Greyed } \\
\text { orange }\end{array}$ \\
\hline IC-484526 & Absent & Absent & $\begin{array}{l}\text { Yellow } \\
\text { Green }\end{array}$ & Very late & Very Short & Present & Absent & Present & Absent & Very Short & Short & Short & Orange \\
\hline IC-484675 & Present & Present & $\begin{array}{l}\text { Yellow } \\
\text { Green }\end{array}$ & Very late & Short & Present & Absent & Present & Present & Medium & Medium & Short & Orange \\
\hline IC-484685 & Absent & Absent & White & Very late & Short & Absent & Absent & Present & Absent & Medium & Long & Medium & $\begin{array}{l}\text { Yellow } \\
\text { orange }\end{array}$ \\
\hline IC-484794 & Present & Present & White & Very late & Short & Absent & Absent & Present & Absent & Medium & Long & Medium & Red orange \\
\hline IC-485072 & Present & Present & White & Medium & Short & Absent & Absent & Present & Absent & Medium & Long & Short & Orange \\
\hline IC-485100 & Present & Present & $\begin{array}{l}\text { Yellow } \\
\text { Green }\end{array}$ & Very late & Short & Present & Absent & Present & Absent & Medium & Medium & Short & Orange \\
\hline IC-485231 & Present & Present & White & Early & Short & Absent & Present & Absent & Absent & Long & Medium & long & $\begin{array}{l}\text { Yellow } \\
\text { orange }\end{array}$ \\
\hline IC-484365 & Present & Present & White & Late & Short & Present & Absent & Present & Absent & Medium & Very Long & Medium & Red orange \\
\hline IC-484390 & Present & Present & White & Very late & Short & Absent & Absent & Present & Absent & Medium & Long & Medium & $\begin{array}{l}\text { Yellow } \\
\text { orange }\end{array}$ \\
\hline IC-484483 & Present & Present & White & Very late & Short & Absent & Absent & Present & Absent & Very Short & Long & Medium & Red orange \\
\hline IC-484542 & Present & Present & White & Very late & Short & Absent & Present & Present & Present & Long & Medium & Medium & Red orange \\
\hline IC-484588 & Present & Present & $\begin{array}{l}\text { Yellow } \\
\text { Green }\end{array}$ & Very late & Short & Absent & Absent & Present & Present & Long & Very short & Medium & Red orange \\
\hline IC-484623 & Present & Present & $\begin{array}{l}\text { Yellow } \\
\text { Green }\end{array}$ & Very late & Medium & Present & Absent & Present & Present & Medium & Long & Medium & $\begin{array}{l}\text { Greyed } \\
\text { orange }\end{array}$ \\
\hline IC-484640 & Present & Present & $\begin{array}{l}\text { Yellow } \\
\text { Green }\end{array}$ & Very late & Short & Present & Absent & Present & Present & Long & Long & Medium & $\begin{array}{l}\text { Greyed } \\
\text { orange }\end{array}$ \\
\hline IC-484643 & Present & Present & White & Very late & Short & Absent & Absent & Present & Present & Very Short & Very long & Medium & Orange \\
\hline IC-484684 & Present & Present & White & Very late & Short & Present & Absent & Present & Present & Medium & Very long & Short & Orange \\
\hline IC-485170 & Present & Present & $\begin{array}{l}\text { Yellow } \\
\text { Green }\end{array}$ & Very late & Short & Absent & Absent & Present & Present & Medium & Medium & Short & $\begin{array}{l}\text { Yellow } \\
\text { orange }\end{array}$ \\
\hline IC-485223 & Present & Present & White & Very late & Short & Absent & Absent & Absent & Absent & Medium & Long & Short & $\begin{array}{l}\text { Yellow } \\
\text { orange }\end{array}$ \\
\hline IC-484364 & Present & Present & White & Very late & Short & Absent & Absent & Present & Absent & Very Short & Very Long & Medium & Orange \\
\hline IC-484537 & Present & Present & White & Very late & Short & Present & Absent & Present & Absent & Medium & Long & Medium & Orange \\
\hline IC-484546 & Present & Present & White & Very late & Short & Absent & Absent & Present & Present & Medium & Long & Medium & Orange \\
\hline IC-484587 & Present & Present & White & Very late & Short & Absent & Absent & Present & Absent & Medium & Short & Short & Orange \\
\hline IC-484622 & Present & Present & White & Very late & Short & Absent & Absent & Present & Absent & Medium & Long & Medium & Orange \\
\hline IC-484674 & Present & Present & White & Very late & Short & Absent & Absent & Present & Absent & Medium & Long & Medium & Orange \\
\hline
\end{tabular}


Int.J.Curr.Microbiol.App.Sci (2018) 7(2): 2058-2071

\begin{tabular}{|c|c|c|c|c|c|c|c|c|c|c|c|c|c|c|}
\hline IC-484739 & Present & \multicolumn{2}{|l|}{ Present } & White & \multicolumn{2}{|l|}{ Short } & Absent & Absent & Present & Absent & Medium & Short & Medium & $\begin{array}{l}\text { Yellow } \\
\text { orange }\end{array}$ \\
\hline IC-484757 & Present & \multicolumn{2}{|l|}{ Present } & White & \multicolumn{2}{|l|}{ Short } & Absent & Absent & Present & Absent & Long & Short & Medium & Orange \\
\hline IC-484777 & \multicolumn{2}{|l|}{ Present } & White & Very late & \multicolumn{2}{|l|}{ Short } & Absent & Absent & Present & Present & Medium & Long & Medium & Orange \\
\hline IC-484779 & Present & Present & $\begin{array}{l}\text { Yellow } \\
\text { Green }\end{array}$ & Very late & \multicolumn{2}{|l|}{ Short } & Absent & Present & Absent & Absent & Medium & Very short & Short & Orange \\
\hline IC-484889 & \multicolumn{2}{|l|}{ Absent } & White & Very late & Short & & Present & Absent & Present & Absent & Medium & Medium & Short & Orange \\
\hline IC-484920 & Present & Present & White & Medium & Mediu & & Absent & Absent & Present & Present & Medium & Very short & Medium & Orange \\
\hline IC-484949 & Absent & Absent & White & Medium & Short & & Absent & Absent & Present & Absent & Medium & Very short & Medium & $\begin{array}{l}\text { Greyed } \\
\text { orange }\end{array}$ \\
\hline IC-484951 & Present & Present & White & Very late & Short & & Absent & Absent & Present & Absent & Medium & Very short & Short & $\begin{array}{l}\text { Yellow } \\
\text { orange }\end{array}$ \\
\hline IC-485054 & Absent & Absent & $\begin{array}{l}\text { Yellow } \\
\text { Green }\end{array}$ & Very late & Short & & Present & Absent & Present & Absent & Medium & Long & Medium & $\begin{array}{l}\text { Yellow } \\
\text { orange }\end{array}$ \\
\hline IC-485099 & Present & Present & White & Late & Short & & Absent & Absent & Present & Absent & Medium & Medium & Short & Orange \\
\hline IC-485115 & Present & Present & White & Very late & Short & & Absent & Absent & Present & Absent & Medium & Long & Medium & $\begin{array}{l}\text { Yellow } \\
\text { orange }\end{array}$ \\
\hline IC-485124 & Present & Present & White & Very late & Short & & Absent & Absent & Present & Absent & Medium & Long & Medium & Orange \\
\hline IC587848 & Present & Present & $\begin{array}{l}\text { Yellow } \\
\text { Green }\end{array}$ & Very late & Short & & Present & Present & Present & Absent & Medium & Very long & Medium & Orange \\
\hline IC587849 & Present & Present & White & Very late & Short & & Absent & Present & Present & Present & Medium & Long & Medium & Red orange \\
\hline IC587850 & Present & Present & $\begin{array}{l}\text { Yellow } \\
\text { Green }\end{array}$ & Very late & Mediu & & Present & Present & Present & Present & Long & Very long & Long & $\begin{array}{l}\text { Yellow } \\
\text { orange }\end{array}$ \\
\hline IC587852 & Present & Present & $\begin{array}{l}\text { Yellow } \\
\text { Green }\end{array}$ & Late & Short & & Absent & Present & Present & Absent & Long & Long & Short & $\begin{array}{l}\text { Yellow } \\
\text { orange }\end{array}$ \\
\hline IC587855 & Present & Present & White & Very late & Short & & Absent & Present & Present & Present & Long & Long & Medium & Red orange \\
\hline IC587856 & Present & Present & $\begin{array}{l}\text { Yellow } \\
\text { Green }\end{array}$ & Very late & Short & & Present & Present & Present & Absent & Long & Long & Medium & Orange \\
\hline IC587857 & Present & Present & $\begin{array}{l}\text { Yellow } \\
\text { Green }\end{array}$ & Very late & Short & & Present & Present & Present & Absent & Medium & Long & Medium & $\begin{array}{l}\text { Yellow } \\
\text { orange }\end{array}$ \\
\hline IC587858 & Present & Present & $\begin{array}{l}\text { Yellow } \\
\text { Green }\end{array}$ & Very late & Short & & Present & Present & Present & Absent & Long & Long & Medium & $\begin{array}{l}\text { Yellow } \\
\text { orange }\end{array}$ \\
\hline IC587859 & Present & Present & White & Very late & Short & & Present & Present & Present & Absent & Medium & Long & Medium & Orange \\
\hline & $\begin{array}{l}\text { Glume } \\
\text { colour }\end{array}$ & $\begin{array}{l}\text { Panicle } \\
\text { length of } \\
\text { branches }\end{array}$ & $\begin{array}{c}\text { Panicle } \\
\text { density at } \\
\text { maturity }\end{array}$ & Panicle shape & $\begin{array}{l}\text { Neck of } \\
\text { panicle } \\
\text { visible } \\
\text { above } \\
\text { sheath }\end{array}$ & $\begin{array}{l}\text { Glume } \\
\text { length }\end{array}$ & $\begin{array}{c}\text { Grain } \\
\text { threshabili } \\
\text { ty }\end{array}$ & $\begin{array}{l}\text { Caryopsis } \\
\text { colour }\end{array}$ & $\begin{array}{c}\text { Grain } \\
\text { shape in } \\
\text { dorsal view }\end{array}$ & $\begin{array}{c}\text { Grain } \\
\text { shape in } \\
\text { profile } \\
\text { view }\end{array}$ & $\begin{array}{c}\text { Grain size } \\
\text { of mark } \\
\text { germ }\end{array}$ & $\begin{array}{l}\text { Grain texture of } \\
\text { endosperm }\end{array}$ & $\begin{array}{l}\text { Grain } \\
\text { colour of } \\
\text { vitreous } \\
\text { albumen }\end{array}$ & $\begin{array}{l}\text { Grain } \\
\text { luster }\end{array}$ \\
\hline IC-485120 & $\begin{array}{l}\text { Green } \\
\text { White }\end{array}$ & Short & $\begin{array}{c}\text { Semi } \\
\text { compact }\end{array}$ & symmetrical & Short & Medium & $\begin{array}{c}\text { Freely } \\
\text { threshable }\end{array}$ & White & Circular & Circular & Medium & 3/4 farinaceous & $\begin{array}{l}\text { Greyed } \\
\text { yellow }\end{array}$ & Present \\
\hline IC-485121 & $\begin{array}{l}\text { Yellow } \\
\text { White }\end{array}$ & Short & $\begin{array}{c}\text { Semi } \\
\text { compact }\end{array}$ & symmetrical & $\begin{array}{l}\text { Very } \\
\text { Short }\end{array}$ & Medium & $\begin{array}{c}\text { Freely } \\
\text { threshable }\end{array}$ & $\begin{array}{l}\text { Yellow } \\
\text { white }\end{array}$ & Eleptical & Eleptical & Medium & $3 / 4$ farinaceous & $\begin{array}{l}\text { Greyed } \\
\text { yellow }\end{array}$ & Absent \\
\hline IC-485251 & $\begin{array}{l}\text { Green } \\
\text { White }\end{array}$ & Short & $\begin{array}{l}\text { Semi } \\
\text { compact }\end{array}$ & symmetrical & Medium & Short & $\begin{array}{c}\text { Freely } \\
\text { threshable }\end{array}$ & $\begin{array}{l}\text { Yellow } \\
\text { orange }\end{array}$ & Circular & Circular & Medium & $3 / 4$ farinaceous & $\begin{array}{l}\text { Greyed } \\
\text { yellow }\end{array}$ & Present \\
\hline IC-484363 & $\begin{array}{l}\text { Grayed } \\
\text { Purple }\end{array}$ & Medium & Semi loose & pyramidal & Very long & $\begin{array}{l}\text { Very } \\
\text { Long }\end{array}$ & $\begin{array}{l}\text { Difficult to } \\
\text { thresh }\end{array}$ & $\begin{array}{l}\text { Yellow } \\
\text { orange }\end{array}$ & Eleptical & Eleptical & Medium & $1 / 2$ vitreous & $\begin{array}{l}\text { Greyed } \\
\text { purpule }\end{array}$ & Absent \\
\hline
\end{tabular}


Int.J.Curr.Microbiol.App.Sci (2018) 7(2): 2058-2071

\begin{tabular}{|c|c|c|c|c|c|c|c|c|c|c|c|c|c|c|}
\hline IC-484374 & $\begin{array}{l}\text { Grayed } \\
\text { Purple }\end{array}$ & Medium & Semi loose & pyramidal & long & $\begin{array}{l}\text { Very } \\
\text { Long }\end{array}$ & $\begin{array}{l}\text { Difficult to } \\
\text { thresh }\end{array}$ & $\begin{array}{l}\text { Yellow } \\
\text { orange }\end{array}$ & Eleptical & Eleptical & Medium & $1 / 2$ vitreous & $\begin{array}{l}\text { Greyed } \\
\text { purpule }\end{array}$ & Present \\
\hline IC-484410 & $\begin{array}{l}\text { Grayed } \\
\text { Purple }\end{array}$ & Medium & Semi loose & pyramidal & long & $\begin{array}{l}\text { Very } \\
\text { Long }\end{array}$ & $\begin{array}{l}\text { Difficult to } \\
\text { thresh }\end{array}$ & $\begin{array}{l}\text { Yellow } \\
\text { orange }\end{array}$ & Eleptical & Eleptical & Medium & $1 / 2$ vitreous & $\begin{array}{l}\text { Greyed } \\
\text { purpule }\end{array}$ & Absent \\
\hline IC-484438 & Grayed Red & Short & Compact & Broader base & long & Medium & $\begin{array}{c}\text { Partly } \\
\text { threshable }\end{array}$ & $\begin{array}{l}\text { Greyed } \\
\text { white }\end{array}$ & Eleptical & Eleptical & Medium & $1 / 2$ vitreous & $\begin{array}{l}\text { Greyed } \\
\text { yellow }\end{array}$ & Absent \\
\hline IC-484448 & $\begin{array}{l}\text { Grayed } \\
\text { Purple }\end{array}$ & Medium & Semi loose & pyramidal & Medium & $\begin{array}{l}\text { Very } \\
\text { Long }\end{array}$ & $\begin{array}{l}\text { Difficult to } \\
\text { thresh }\end{array}$ & $\begin{array}{l}\text { Greyed } \\
\text { orange }\end{array}$ & $\begin{array}{l}\text { Nerrow } \\
\text { eleptical }\end{array}$ & $\begin{array}{l}\text { Nerrow } \\
\text { eleptical }\end{array}$ & Medium & $1 / 2$ vitreous & $\begin{array}{l}\text { Greyed } \\
\text { yellow }\end{array}$ & Absent \\
\hline IC-484471 & $\begin{array}{l}\text { Green } \\
\text { White }\end{array}$ & Short & $\begin{array}{l}\text { Semi } \\
\text { compact }\end{array}$ & symmetrical & Medium & Short & $\begin{array}{c}\text { Partly } \\
\text { threshable }\end{array}$ & $\begin{array}{l}\text { Yellow } \\
\text { orange }\end{array}$ & Circular & Circular & Large & $3 / 4$ farinaceous & $\begin{array}{l}\text { Greyed } \\
\text { orange }\end{array}$ & Present \\
\hline IC-484547 & $\begin{array}{l}\text { Grayed } \\
\text { Purple }\end{array}$ & Medium & Semi loose & pyramidal & long & $\begin{array}{l}\text { Very } \\
\text { Long }\end{array}$ & $\begin{array}{l}\text { Difficult to } \\
\text { thresh }\end{array}$ & White & Eleptical & Eleptical & Large & $1 / 2$ vitreous & $\begin{array}{l}\text { Greyed } \\
\text { yellow }\end{array}$ & Absent \\
\hline IC-484559 & $\begin{array}{l}\text { Grayed } \\
\text { Purple }\end{array}$ & Medium & Semi loose & pyramidal & Medium & $\begin{array}{l}\text { Very } \\
\text { Long }\end{array}$ & $\begin{array}{l}\text { Difficult to } \\
\text { thresh }\end{array}$ & White & Eleptical & Eleptical & Large & $1 / 2$ vitreous & $\begin{array}{l}\text { Greyed } \\
\text { yellow }\end{array}$ & Present \\
\hline IC-484606 & $\begin{array}{c}\text { Grayed Red } \\
*\end{array}$ & Short & $\begin{array}{c}\text { Semi } \\
\text { compact }\end{array}$ & Broader base & Medium & Medium & $\begin{array}{c}\text { Freely } \\
\text { threshable }\end{array}$ & $\begin{array}{l}\text { Yellow } \\
\text { white }\end{array}$ & Circular & Circular & Medium & 3/4 farinaceous & $\begin{array}{l}\text { Greyed } \\
\text { yellow }\end{array}$ & Absent \\
\hline IC-484621 & $\begin{array}{l}\text { Grayed } \\
\text { Purple }\end{array}$ & Medium & Semi loose & pyramidal & $\begin{array}{l}\text { Very } \\
\text { Short }\end{array}$ & $\begin{array}{l}\text { Very } \\
\text { Long }\end{array}$ & $\begin{array}{l}\text { Difficult to } \\
\text { thresh }\end{array}$ & $\begin{array}{l}\text { Greyed } \\
\text { white }\end{array}$ & Eleptical & Eleptical & Medium & $1 / 2$ vitreous & $\begin{array}{l}\text { Greyed } \\
\text { yellow }\end{array}$ & Absent \\
\hline IC-484657 & $\begin{array}{l}\text { Grayed } \\
\text { Purple }\end{array}$ & Medium & Semi loose & pyramidal & long & $\begin{array}{l}\text { Very } \\
\text { Long }\end{array}$ & $\begin{array}{l}\text { Difficult to } \\
\text { thresh }\end{array}$ & $\begin{array}{l}\text { Greyed } \\
\text { white }\end{array}$ & Eleptical & Eleptical & Large & $1 / 2$ vitreous & $\begin{array}{l}\text { Greyed } \\
\text { yellow }\end{array}$ & Absent \\
\hline IC-484678 & $\begin{array}{l}\text { Green } \\
\text { White }\end{array}$ & Short & $\begin{array}{l}\text { Semi } \\
\text { compact }\end{array}$ & pyramidal & Medium & Medium & $\begin{array}{c}\text { Freely } \\
\text { threshable }\end{array}$ & $\begin{array}{l}\text { Yellow } \\
\text { white }\end{array}$ & Circular & Circular & Large & $3 / 4$ farinaceous & $\begin{array}{l}\text { Greyed } \\
\text { yellow }\end{array}$ & Absent \\
\hline IC-484875 & $\begin{array}{l}\text { Grayed } \\
\text { Purple }\end{array}$ & Medium & Semi loose & pyramidal & long & $\begin{array}{l}\text { Very } \\
\text { Long }\end{array}$ & $\begin{array}{l}\text { Difficult to } \\
\text { thresh }\end{array}$ & $\begin{array}{l}\text { Greyed } \\
\text { orange }\end{array}$ & Eleptical & Eleptical & Large & $1 / 2$ vitreous & $\begin{array}{l}\text { Greyed } \\
\text { orange }\end{array}$ & Absent \\
\hline IC-485113 & $\begin{array}{l}\text { Grayed } \\
\text { Purple }\end{array}$ & Medium & Semi loose & pyramidal & Medium & $\begin{array}{l}\text { Very } \\
\text { Long }\end{array}$ & $\begin{array}{l}\text { Difficult to } \\
\text { thresh }\end{array}$ & $\begin{array}{l}\text { Greyed } \\
\text { orange }\end{array}$ & Eleptical & Eleptical & Medium & Full farinaceous & $\begin{array}{l}\text { Greyed } \\
\text { purpule }\end{array}$ & Absent \\
\hline IC-485119 & $\begin{array}{l}\text { Grayed } \\
\text { Purple }\end{array}$ & Medium & Semi loose & pyramidal & Medium & $\begin{array}{l}\text { Very } \\
\text { Long }\end{array}$ & $\begin{array}{l}\text { Difficult to } \\
\text { thresh }\end{array}$ & White & Eleptical & Eleptical & Large & $3 / 4$ farinaceous & $\begin{array}{l}\text { Greyed } \\
\text { yellow }\end{array}$ & Present \\
\hline IC-485132 & $\begin{array}{l}\text { Grayed } \\
\text { Purple }\end{array}$ & Medium & Semi loose & pyramidal & Short & Long & $\begin{array}{l}\text { Difficult to } \\
\text { thresh }\end{array}$ & White & Eleptical & Eleptical & Medium & $1 / 2$ vitreous & $\begin{array}{l}\text { Greyed } \\
\text { yellow }\end{array}$ & Present \\
\hline IC-485160 & $\begin{array}{l}\text { Green } \\
\text { White }\end{array}$ & Short & $\begin{array}{l}\text { Semi } \\
\text { compact }\end{array}$ & symmetrical & Medium & Short & $\begin{array}{c}\text { Freely } \\
\text { threshable }\end{array}$ & $\begin{array}{l}\text { Yellow } \\
\text { white }\end{array}$ & Circular & Circular & Medium & 3/4 farinaceous & $\begin{array}{l}\text { Greyed } \\
\text { yellow }\end{array}$ & Absent \\
\hline IC-485237 & $\begin{array}{l}\text { Grayed } \\
\text { Purple }\end{array}$ & Medium & Semi loose & pyramidal & Very long & $\begin{array}{l}\text { Very } \\
\text { Long }\end{array}$ & $\begin{array}{l}\text { Difficult to } \\
\text { thresh }\end{array}$ & White & Eleptical & Circular & Medium & $1 / 2$ vitreous & $\begin{array}{l}\text { Greyed } \\
\text { yellow }\end{array}$ & Absent \\
\hline IC-485242 & $\begin{array}{l}\text { Grayed } \\
\text { Purple }\end{array}$ & Medium & Semi loose & pyramidal & long & $\begin{array}{l}\text { Very } \\
\text { Long }\end{array}$ & $\begin{array}{c}\text { Freely } \\
\text { threshable }\end{array}$ & $\begin{array}{l}\text { Yellow } \\
\text { white }\end{array}$ & Eleptical & Eleptical & Medium & $1 / 2$ vitreous & $\begin{array}{l}\text { Greyed } \\
\text { yellow }\end{array}$ & Present \\
\hline EC-524468 & $\begin{array}{l}\text { Yellow } \\
\text { White }\end{array}$ & Medium & Loose & pyramidal & Medium & Long & $\begin{array}{c}\text { Partly } \\
\text { threshable }\end{array}$ & White & Eleptical & Eleptical & Medium & $1 / 2$ vitreous & $\begin{array}{l}\text { Greyed } \\
\text { yellow }\end{array}$ & Present \\
\hline IC-253535 & $\begin{array}{l}\text { Grayed } \\
\text { Purple }\end{array}$ & long & Very Long* & pyramidal & Very long & Medium & $\begin{array}{c}\text { Freely } \\
\text { threshable }\end{array}$ & $\begin{array}{l}\text { Yellow } \\
\text { white }\end{array}$ & Circular & Circular & Large & $1 / 2$ vitreous & $\begin{array}{l}\text { Greyed } \\
\text { purpule }\end{array}$ & Present \\
\hline IC-289225 & $\begin{array}{l}\text { Grayed } \\
\text { Yellow }\end{array}$ & Medium & Loose & pyramidal & Medium & $\begin{array}{l}\text { Very } \\
\text { Long }\end{array}$ & $\begin{array}{l}\text { Difficult to } \\
\text { thresh }\end{array}$ & White & Eleptical & Eleptical & Large & Full farinaceous & $\begin{array}{l}\text { Greyed } \\
\text { yellow }\end{array}$ & Present \\
\hline IC-484369 & $\begin{array}{c}\text { Grayed Red } \\
*\end{array}$ & Short & Compact & Broader base & very short & Medium & $\begin{array}{c}\text { Partly } \\
\text { threshable }\end{array}$ & White & Circular & Circular & Large & $3 / 4$ farinaceous & $\begin{array}{l}\text { Greyed } \\
\text { yellow }\end{array}$ & Present \\
\hline IC-484437 & $\begin{array}{l}\text { Grayed } \\
\text { Yellow }\end{array}$ & Short & $\begin{array}{c}\text { Semi } \\
\text { compact }\end{array}$ & Broader base & Medium & Medium & $\begin{array}{c}\text { Freely } \\
\text { threshable }\end{array}$ & $\begin{array}{l}\text { Yellow } \\
\text { white }\end{array}$ & Circular & Circular & Medium & $3 / 4$ farinaceous & $\begin{array}{l}\text { Greyed } \\
\text { yellow }\end{array}$ & Absent \\
\hline IC-484475 & $\begin{array}{l}\text { Green } \\
\text { White }\end{array}$ & Medium & Semi loose & Broader at top & $\begin{array}{l}\text { Very } \\
\text { short }\end{array}$ & Medium & $\begin{array}{c}\text { Freely } \\
\text { threshable }\end{array}$ & $\begin{array}{l}\text { Greyed } \\
\text { white }\end{array}$ & Eliptical & Circular & Medium & $3 / 4$ farinaceous & $\begin{array}{l}\text { Greyed } \\
\text { yellow }\end{array}$ & Absent \\
\hline IC-484503 & $\begin{array}{l}\text { Green } \\
\text { White }\end{array}$ & Short & $\begin{array}{l}\text { Semi } \\
\text { compact }\end{array}$ & Broader base & $\begin{array}{l}\text { Very } \\
\text { short }\end{array}$ & Long & $\begin{array}{c}\text { Freely } \\
\text { threshable }\end{array}$ & $\begin{array}{l}\text { Yellow } \\
\text { white }\end{array}$ & Circular & Circular & Medium & $3 / 4$ farinaceous & $\begin{array}{l}\text { Greyed } \\
\text { yellow }\end{array}$ & Present \\
\hline IC-484522 & $\begin{array}{l}\text { Grayed } \\
\text { Yellow }\end{array}$ & Short & $\begin{array}{c}\text { Semi } \\
\text { compact }\end{array}$ & symmetrical & Short & Short & $\begin{array}{c}\text { Freely } \\
\text { threshable }\end{array}$ & $\begin{array}{c}\text { Greyed } \\
\text { white }\end{array}$ & Circular & Circular & Large & $3 / 4$ farinaceous & $\begin{array}{l}\text { Greyed } \\
\text { yellow }\end{array}$ & Absent \\
\hline IC-484526 & $\begin{array}{l}\text { Green } \\
\text { White }\end{array}$ & Short & $\begin{array}{c}\text { Semi } \\
\text { compact }\end{array}$ & symmetrical & Medium & Long & $\begin{array}{c}\text { Freely } \\
\text { threshable }\end{array}$ & $\begin{array}{l}\text { Greyed } \\
\text { white }\end{array}$ & Circular & Circular & Large & $3 / 4$ farinaceous & $\begin{array}{l}\text { Greyed } \\
\text { purpule }\end{array}$ & Absent \\
\hline
\end{tabular}


Int.J.Curr.Microbiol.App.Sci (2018) 7(2): 2058-2071

\begin{tabular}{|c|c|c|c|c|c|c|c|c|c|c|c|c|c|c|}
\hline IC-484675 & $\begin{array}{l}\text { Grayed } \\
\text { Orange }\end{array}$ & Short & $\begin{array}{l}\text { Semi } \\
\text { compact }\end{array}$ & symmetrical & Short & Short & $\begin{array}{c}\text { Freely } \\
\text { threshable }\end{array}$ & $\begin{array}{l}\text { Yellow } \\
\text { white }\end{array}$ & Circular & Circular & Medium & $3 / 4$ farinaceous & $\begin{array}{l}\text { Greyed } \\
\text { yellow }\end{array}$ & Absent \\
\hline IC-484685 & $\begin{array}{l}\text { Green } \\
\text { White }\end{array}$ & Short & $\begin{array}{l}\text { Semi } \\
\text { compact }\end{array}$ & pyramidal & Short & Medium & $\begin{array}{c}\text { Freely } \\
\text { threshable }\end{array}$ & $\begin{array}{l}\text { Yellow } \\
\text { orange }\end{array}$ & Circular & Circular & Large & $3 / 4$ farinaceous & $\begin{array}{l}\text { Greyed } \\
\text { orange }\end{array}$ & Present \\
\hline IC-484794 & $\begin{array}{l}\text { Grayed } \\
\text { Purple }\end{array}$ & Medium & Semi loose & pyramidal & Short & $\begin{array}{l}\text { Very } \\
\text { Long }\end{array}$ & $\begin{array}{l}\text { Difficult to } \\
\text { thresh }\end{array}$ & White & Eleptical & Eleptical & Medium & Full farinaceous & $\begin{array}{l}\text { Greyed } \\
\text { yellow }\end{array}$ & Present \\
\hline IC-485072 & $\begin{array}{l}\text { Grayed } \\
\text { Purple }\end{array}$ & Medium & Semi loose & pyramidal & Short & $\begin{array}{l}\text { Very } \\
\text { Long }\end{array}$ & $\begin{array}{l}\text { Difficult to } \\
\text { thresh }\end{array}$ & White & Eleptical & Eleptical & Large & $1 / 2$ vitreous & $\begin{array}{l}\text { Greyed } \\
\text { yellow }\end{array}$ & Present \\
\hline IC-485100 & $\begin{array}{l}\text { Green } \\
\text { White }\end{array}$ & Short & $\begin{array}{l}\text { Semi } \\
\text { compact }\end{array}$ & symmetrical & Short & Short & $\begin{array}{c}\text { Freely } \\
\text { threshable }\end{array}$ & $\begin{array}{l}\text { Yellow } \\
\text { white }\end{array}$ & Circular & Circular & Medium & $3 / 4$ farinaceous & $\begin{array}{l}\text { Greyed } \\
\text { yellow }\end{array}$ & Present \\
\hline IC-485231 & $\begin{array}{l}\text { Grayed } \\
\text { Purple }\end{array}$ & Short & Compact & Broader base & $\begin{array}{l}\text { Very } \\
\text { Short }\end{array}$ & Medium & $\begin{array}{c}\text { Freely } \\
\text { threshable }\end{array}$ & $\begin{array}{l}\text { Yellow } \\
\text { white }\end{array}$ & Circular & Circular & Large & $3 / 4$ farinaceous & $\begin{array}{l}\text { Greyed } \\
\text { yellow }\end{array}$ & Present \\
\hline IC-484365 & $\begin{array}{l}\text { Grayed } \\
\text { Purple }\end{array}$ & Medium & Loose & pyramidal & Medium & Long & $\begin{array}{l}\text { Difficult to } \\
\text { thresh }\end{array}$ & $\begin{array}{l}\text { Yellow } \\
\text { orange }\end{array}$ & Circular & Circular & Large & $3 / 4$ farinaceous & $\begin{array}{l}\text { Greyed } \\
\text { orange }\end{array}$ & Present \\
\hline IC-484390 & $\begin{array}{c}\text { Grayed Red } \\
*\end{array}$ & Medium & Semi loose & pyramidal & Medium & $\begin{array}{l}\text { Very } \\
\text { Long }\end{array}$ & $\begin{array}{l}\text { Difficult to } \\
\text { thresh }\end{array}$ & White & Eleptical & Eleptical & Large & $1 / 2$ vitreous & $\begin{array}{l}\text { Greyed } \\
\text { yellow }\end{array}$ & Present \\
\hline IC-484483 & $\begin{array}{l}\text { Grayed } \\
\text { Purple }\end{array}$ & Medium & Semi loose & pyramidal & Long & $\begin{array}{l}\text { Very } \\
\text { Long }\end{array}$ & $\begin{array}{l}\text { Difficult to } \\
\text { thresh }\end{array}$ & White & Eleptical & Eleptical & Medium & $1 / 2$ vitreous & $\begin{array}{l}\text { Greyed } \\
\text { yellow }\end{array}$ & Present \\
\hline IC-484542 & $\begin{array}{l}\text { Grayed } \\
\text { Orange }\end{array}$ & Short & Compact & Broader base & Short & Short & $\begin{array}{c}\text { Partly } \\
\text { threshable }\end{array}$ & $\begin{array}{l}\text { Yellow } \\
\text { orange }\end{array}$ & Circular & Circular & Large & $3 / 4$ farinaceous & $\begin{array}{l}\text { Greyed } \\
\text { orange }\end{array}$ & Present \\
\hline IC-484588 & $\begin{array}{l}\text { Grayed } \\
\text { Purple }\end{array}$ & Short & $\begin{array}{l}\text { Semi } \\
\text { compact }\end{array}$ & pyramidal & Medium & Medium & $\begin{array}{c}\text { Partly } \\
\text { threshable }\end{array}$ & $\begin{array}{l}\text { Yellow } \\
\text { white }\end{array}$ & Eleptical & Circular & Large & $3 / 4$ farinaceous & $\begin{array}{l}\text { Greyed } \\
\text { yellow }\end{array}$ & Present \\
\hline IC-484623 & $\begin{array}{l}\text { Grayed } \\
\text { Purple }\end{array}$ & Short & $\begin{array}{l}\text { Semi } \\
\text { compact }\end{array}$ & symmetrical & Medium & Long & $\begin{array}{c}\text { Partly } \\
\text { threshable }\end{array}$ & $\begin{array}{l}\text { Yellow } \\
\text { white }\end{array}$ & Eleptical & Eleptical & Large & $1 / 2$ vitreous & $\begin{array}{l}\text { Greyed } \\
\text { yellow }\end{array}$ & Present \\
\hline IC-484640 & $\begin{array}{l}\text { Grayed } \\
\text { Purple }\end{array}$ & Short & $\begin{array}{c}\text { Semi } \\
\text { compact }\end{array}$ & symmetrical & Short & Long & $\begin{array}{c}\text { Partly } \\
\text { threshable }\end{array}$ & $\begin{array}{l}\text { Yellow } \\
\text { white }\end{array}$ & Eleptical & Eleptical & Large & $1 / 2$ vitreous & $\begin{array}{l}\text { Greyed } \\
\text { yellow }\end{array}$ & Present \\
\hline IC-484643 & $\begin{array}{l}\text { Grayed } \\
\text { Purple }\end{array}$ & Medium & Semi loose & pyramidal & Medium & $\begin{array}{l}\text { Very } \\
\text { Long }\end{array}$ & $\begin{array}{l}\text { Difficult to } \\
\text { thresh }\end{array}$ & $\begin{array}{l}\text { Greyed } \\
\text { orange }\end{array}$ & Eleptical & Eleptical & Medium & Full farinaceous & $\begin{array}{l}\text { Greyed } \\
\text { yellow }\end{array}$ & Absent \\
\hline IC-484684 & $\begin{array}{l}\text { Grayed } \\
\text { Purple }\end{array}$ & Medium & Semi loose & pyramidal & Short & $\begin{array}{l}\text { Very } \\
\text { Long }\end{array}$ & $\begin{array}{l}\text { Difficult to } \\
\text { thresh }\end{array}$ & $\begin{array}{l}\text { Greyed } \\
\text { orange }\end{array}$ & Eleptical & Eleptical & Medium & $1 / 2$ vitreous & $\begin{array}{l}\text { Greyed } \\
\text { orange }\end{array}$ & Absent \\
\hline IC-485170 & $\begin{array}{l}\text { Green } \\
\text { White }\end{array}$ & Short & $\begin{array}{l}\text { Semi } \\
\text { compact }\end{array}$ & symmetrical & Medium & Medium & $\begin{array}{c}\text { Freely } \\
\text { threshable }\end{array}$ & $\begin{array}{l}\text { Yellow } \\
\text { white }\end{array}$ & Circular & Circular & Medium & $3 / 4$ farinaceous & $\begin{array}{l}\text { Greyed } \\
\text { yellow }\end{array}$ & Absent \\
\hline IC-485223 & $\begin{array}{l}\text { Green } \\
\text { White }\end{array}$ & Short & Compact & symmetrical & Medium & Medium & $\begin{array}{c}\text { Partly } \\
\text { threshable }\end{array}$ & White & Circular & Circular & Medium & $3 / 4$ farinaceous & $\begin{array}{l}\text { Greyed } \\
\text { yellow }\end{array}$ & Absent \\
\hline IC-484364 & $\begin{array}{l}\text { Grayed } \\
\text { Purple }\end{array}$ & Medium & Semi loose & pyramidal & Long & $\begin{array}{l}\text { Very } \\
\text { Long }\end{array}$ & $\begin{array}{l}\text { Difficult to } \\
\text { thresh }\end{array}$ & White & Eliptical & Circular & Large & $1 / 2$ vitreous & $\begin{array}{l}\text { Greyed } \\
\text { yellow }\end{array}$ & Present \\
\hline IC-484537 & $\begin{array}{l}\text { Grayed } \\
\text { Purple }\end{array}$ & Medium & Semi loose & pyramidal & Medium & $\begin{array}{l}\text { Very } \\
\text { Long }\end{array}$ & $\begin{array}{l}\text { Difficult to } \\
\text { thresh }\end{array}$ & White & Eliptical & Eliptical & Large & $1 / 2$ vitreous & $\begin{array}{l}\text { Greyed } \\
\text { yellow }\end{array}$ & Present \\
\hline IC-484546 & $\begin{array}{l}\text { Grayed } \\
\text { Purple }\end{array}$ & Medium & Semi loose & pyramidal & Long & $\begin{array}{l}\text { Very } \\
\text { Long }\end{array}$ & $\begin{array}{l}\text { Difficult to } \\
\text { thresh }\end{array}$ & White & Eliptical & Eliptical & Medium & Full farinaceous & $\begin{array}{l}\text { Greyed } \\
\text { yellow }\end{array}$ & Present \\
\hline IC-484587 & $\begin{array}{l}\text { Grayed } \\
\text { Purple }\end{array}$ & Medium & Semi loose & pyramidal & Very long & $\begin{array}{l}\text { Very } \\
\text { Long }\end{array}$ & $\begin{array}{l}\text { Difficult to } \\
\text { thresh }\end{array}$ & White & Eliptical & Eliptical & Large & $1 / 2$ vitreous & $\begin{array}{l}\text { Greyed } \\
\text { yellow }\end{array}$ & Present \\
\hline IC-484622 & $\begin{array}{l}\text { Grayed } \\
\text { Purple }\end{array}$ & Medium & Semi loose & pyramidal & Medium & Medium & $\begin{array}{l}\text { Difficult to } \\
\text { thresh }\end{array}$ & White & Eliptical & Eliptical & Large & $1 / 2$ vitreous & $\begin{array}{l}\text { Greyed } \\
\text { yellow }\end{array}$ & Present \\
\hline IC-484674 & $\begin{array}{l}\text { Grayed } \\
\text { Purple }\end{array}$ & Medium & Semi loose & pyramidal & Medium & Long & $\begin{array}{l}\text { Difficult to } \\
\text { thresh }\end{array}$ & White & Eliptical & Eliptical & Medium & $1 / 2$ vitreous & $\begin{array}{l}\text { Greyed } \\
\text { yellow }\end{array}$ & Present \\
\hline IC-484739 & $\begin{array}{l}\text { Grayed } \\
\text { Purple }\end{array}$ & Medium & Semi loose & pyramidal & Long & Long & $\begin{array}{l}\text { Difficult to } \\
\text { thresh }\end{array}$ & White & Eliptical & Eliptical & Large & $3 / 4$ farinaceous & $\begin{array}{l}\text { Greyed } \\
\text { orange }\end{array}$ & Present \\
\hline IC-484757 & $\begin{array}{l}\text { Grayed } \\
\text { Purple }\end{array}$ & Medium & Semi loose & pyramidal & Long & $\begin{array}{l}\text { Very } \\
\text { Long }\end{array}$ & $\begin{array}{l}\text { Difficult to } \\
\text { thresh }\end{array}$ & White & Eliptical & Eliptical & Large & $1 / 2$ vitreous & $\begin{array}{l}\text { Greyed } \\
\text { orange }\end{array}$ & Absent \\
\hline IC-484777 & $\begin{array}{l}\text { Grayed } \\
\text { Purple }\end{array}$ & Medium & Semi loose & pyramidal & Medium & $\begin{array}{l}\text { Very } \\
\text { Long }\end{array}$ & $\begin{array}{l}\text { Difficult to } \\
\text { thresh }\end{array}$ & White & Eliptical & Eliptical & Large & $1 / 2$ vitreous & $\begin{array}{l}\text { Greyed } \\
\text { yellow }\end{array}$ & Present \\
\hline IC-484779 & $\begin{array}{l}\text { Grayed } \\
\text { Purple }\end{array}$ & Medium & Semi loose & pyramidal & Medium & $\begin{array}{l}\text { Very } \\
\text { Long }\end{array}$ & $\begin{array}{l}\text { Difficult to } \\
\text { thresh }\end{array}$ & $\begin{array}{l}\text { Greyed } \\
\text { orange }\end{array}$ & Eliptical & Eliptical & Large & $1 / 2$ vitreous & $\begin{array}{l}\text { Greyed } \\
\text { yellow }\end{array}$ & Absent \\
\hline
\end{tabular}


Int.J.Curr.Microbiol.App.Sci (2018) 7(2): 2058-2071

\begin{tabular}{|c|c|c|c|c|c|c|c|c|c|c|c|c|c|c|}
\hline IC-484889 & $\begin{array}{l}\text { Grayed } \\
\text { Orange }\end{array}$ & Short & $\begin{array}{l}\text { Semi } \\
\text { compact }\end{array}$ & symmetrical & Medium & Short & $\begin{array}{c}\text { Freely } \\
\text { threshable }\end{array}$ & $\begin{array}{l}\text { Yellow } \\
\text { white }\end{array}$ & Circular & Circular & Large & 3/4 farinaceous & $\begin{array}{l}\text { Greyed } \\
\text { yellow }\end{array}$ & Present \\
\hline IC-484920 & $\begin{array}{l}\text { Grayed } \\
\text { Purple }\end{array}$ & Medium & Semi loose & pyramidal & Medium & $\begin{array}{l}\text { Very } \\
\text { Long }\end{array}$ & $\begin{array}{l}\text { Difficult to } \\
\text { thresh }\end{array}$ & White & Eliptical & Eliptical & Large & 3/4 farinaceous & $\begin{array}{l}\text { Greyed } \\
\text { yellow }\end{array}$ & Present \\
\hline IC-484949 & $\begin{array}{l}\text { Green } \\
\text { White }\end{array}$ & Medium & Semi loose & pyramidal & Medium & $\begin{array}{l}\text { Very } \\
\text { Long }\end{array}$ & $\begin{array}{c}\text { Partly } \\
\text { threshable }\end{array}$ & White & Eliptical & Eliptical & Large & $1 / 2$ vitreous & $\begin{array}{l}\text { Greyed } \\
\text { yellow }\end{array}$ & Present \\
\hline IC-484951 & $\begin{array}{l}\text { Grayed } \\
\text { Purple }\end{array}$ & Medium & Semi loose & pyramidal & Very long & $\begin{array}{l}\text { Very } \\
\text { Long }\end{array}$ & $\begin{array}{l}\text { Difficult to } \\
\text { thresh }\end{array}$ & $\begin{array}{l}\text { Greyed } \\
\text { orange }\end{array}$ & Eliptical & Eliptical & Medium & $1 / 2$ vitreous & $\begin{array}{l}\text { Greyed } \\
\text { orange }\end{array}$ & Absent \\
\hline IC-485054 & $\begin{array}{l}\text { Green } \\
\text { White }\end{array}$ & Short & $\begin{array}{c}\text { Semi } \\
\text { compact }\end{array}$ & symmetrical & Long & Medium & $\begin{array}{c}\text { Freely } \\
\text { threshable }\end{array}$ & $\begin{array}{l}\text { Yellow } \\
\text { white }\end{array}$ & Circular & Circular & Large & $3 / 4$ farinaceous & $\begin{array}{l}\text { Greyed } \\
\text { yellow }\end{array}$ & Present \\
\hline IC-485099 & $\begin{array}{c}\text { Grayed Red } \\
*\end{array}$ & Medium & Semi loose & pyramidal & $\begin{array}{l}\text { Very } \\
\text { short }\end{array}$ & $\begin{array}{l}\text { Very } \\
\text { Long }\end{array}$ & $\begin{array}{c}\text { Partly } \\
\text { threshable }\end{array}$ & White & Eliptical & Eliptical & Medium & $1 / 2$ vitreous & $\begin{array}{l}\text { Greyed } \\
\text { yellow }\end{array}$ & Absent \\
\hline IC-485115 & $\begin{array}{l}\text { Grayed } \\
\text { Purple }\end{array}$ & Medium & Semi loose & pyramidal & Medium & $\begin{array}{l}\text { Very } \\
\text { Long }\end{array}$ & $\begin{array}{l}\text { Difficult to } \\
\text { thresh }\end{array}$ & White & Eliptical & Eliptical & Large & $1 / 2$ vitreous & $\begin{array}{l}\text { Greyed } \\
\text { yellow }\end{array}$ & Present \\
\hline IC-485124 & $\begin{array}{l}\text { Grayed } \\
\text { Purple }\end{array}$ & Medium & Semi loose & symmetrical & Medium & $\begin{array}{l}\text { Very } \\
\text { Long }\end{array}$ & $\begin{array}{l}\text { Difficult to } \\
\text { thresh }\end{array}$ & White & Eliptical & Eliptical & Medium & $1 / 2$ vitreous & $\begin{array}{l}\text { Greyed } \\
\text { yellow }\end{array}$ & Absent \\
\hline IC587848 & $\begin{array}{l}\text { Grayed } \\
\text { Orange }\end{array}$ & Short & Semi loose & Broader base & Medium & Medium & $\begin{array}{l}\text { Difficult to } \\
\text { thresh }\end{array}$ & White & Eliptical & Eliptical & & $1 / 2$ vitreous & $\begin{array}{l}\text { Greyed } \\
\text { yellow }\end{array}$ & Absent \\
\hline IC587849 & $\begin{array}{l}\text { Green } \\
\text { White }\end{array}$ & Short & Compact & Broader base & $\begin{array}{l}\text { Very } \\
\text { short }\end{array}$ & Medium & $\begin{array}{c}\text { Partly } \\
\text { threshable }\end{array}$ & $\begin{array}{l}\text { Yellow } \\
\text { orange }\end{array}$ & Circular & Circular & Large & 3/4 farinaceous & $\begin{array}{l}\text { Greyed } \\
\text { yellow }\end{array}$ & Present \\
\hline IC587850 & $\begin{array}{l}\text { Grayed } \\
\text { Yellow }\end{array}$ & Short & $\begin{array}{l}\text { Semi } \\
\text { compact }\end{array}$ & Broader base & Long & Medium & $\begin{array}{c}\text { Freely } \\
\text { threshable }\end{array}$ & White & Eliptical & Eliptical & Large & $1 / 2$ vitreous & $\begin{array}{l}\text { Greyed } \\
\text { yellow }\end{array}$ & Present \\
\hline IC587852 & $\begin{array}{l}\text { Grayed } \\
\text { Yellow }\end{array}$ & Short & $\begin{array}{l}\text { Semi } \\
\text { compact }\end{array}$ & Broader base & $\begin{array}{l}\text { Very } \\
\text { short }\end{array}$ & Medium & $\begin{array}{c}\text { Freely } \\
\text { threshable }\end{array}$ & $\begin{array}{l}\text { Green } \\
\text { white }\end{array}$ & Circular & Circular & Large & 3/4 farinaceous & $\begin{array}{l}\text { Greyed } \\
\text { yellow }\end{array}$ & Present \\
\hline IC587855 & $\begin{array}{l}\text { Grayed } \\
\text { Orange }\end{array}$ & Short & $\begin{array}{c}\text { Semi } \\
\text { compact }\end{array}$ & Broader base & $\begin{array}{l}\text { Very } \\
\text { short }\end{array}$ & Medium & $\begin{array}{c}\text { Freely } \\
\text { threshable }\end{array}$ & $\begin{array}{l}\text { Yellow } \\
\text { orange }\end{array}$ & Circular & Circular & Large & $3 / 4$ farinaceous & $\begin{array}{l}\text { Greyed } \\
\text { orange }\end{array}$ & Present \\
\hline IC587856 & $\begin{array}{c}\text { Grayed Red } \\
*\end{array}$ & Short & $\begin{array}{l}\text { Semi } \\
\text { compact }\end{array}$ & Broader base & Medium & Long & $\begin{array}{c}\text { Freely } \\
\text { threshable }\end{array}$ & $\begin{array}{l}\text { Yellow } \\
\text { white }\end{array}$ & Circular & Circular & Large & $3 / 4$ farinaceous & $\begin{array}{l}\text { Greyed } \\
\text { yellow }\end{array}$ & Absent \\
\hline IC587857 & $\begin{array}{l}\text { Grayed } \\
\text { Yellow }\end{array}$ & Short & $\begin{array}{l}\text { Semi } \\
\text { compact }\end{array}$ & Broader base & $\begin{array}{l}\text { Very } \\
\text { short }\end{array}$ & Medium & $\begin{array}{c}\text { Freely } \\
\text { threshable }\end{array}$ & White & Eliptical & Eliptical & Large & Full farinaceous & $\begin{array}{l}\text { Greyed } \\
\text { yellow }\end{array}$ & Present \\
\hline IC587858 & $\begin{array}{l}\text { Grayed } \\
\text { Yellow }\end{array}$ & Short & $\begin{array}{c}\text { Semi } \\
\text { compact }\end{array}$ & Broader base & $\begin{array}{l}\text { Very } \\
\text { short }\end{array}$ & Short & $\begin{array}{c}\text { Freely } \\
\text { threshable }\end{array}$ & $\begin{array}{l}\text { Yellow } \\
\text { white }\end{array}$ & Circular & Circular & Large & $3 / 4$ farinaceous & $\begin{array}{l}\text { Greyed } \\
\text { yellow }\end{array}$ & Present \\
\hline IC587859 & $\begin{array}{l}\text { Green } \\
\text { White }\end{array}$ & Short & $\begin{array}{c}\text { Semi } \\
\text { compact }\end{array}$ & symmetrical & Medium & Medium & $\begin{array}{c}\text { Freely } \\
\text { threshable }\end{array}$ & $\begin{array}{l}\text { Yellow } \\
\text { white }\end{array}$ & Circular & Circular & Large & $3 / 4$ farinaceous & $\begin{array}{l}\text { Greyed } \\
\text { yellow }\end{array}$ & Absent \\
\hline
\end{tabular}




\section{After threshing}

After threshing genotypes were classified on the basis of caryopsis colour, grain shape in dorsal view, grain shape in profile view, grain size of mark of germ, grain texture of endosperm (in longitudinal section), grain colour of vitreous albumen and grain luster. Genotypes were characterized into four groups viz., white (31 genotypes), yellow white (20 genotypes), yellow orange (10 genotypes), greyed white (7 genotype) and grayed orange ( 7 genotypes) on the basis of caryopsis colour. However, on the basis of grain textures of endosperm genotypes were divided into four groups namely, $3 / 4$ vitreous (26 genotypes), $1 / 2$ vitreous (36 genotypes), $3 / 4$ farinaceous ( 7 genotypes) and full farinaceous (6 genotypes). On the basis of grain shape in dorsal view genotypes were characterized into three groups namely, circular (28 genotypes), elliptic (46 genotypes) and narrow elliptic (1 genotype). Whereas, on the basis of grain shape in profile view genotypes were also divided into three groups viz., circular (32 genotypes), elliptic (42 genotypes) and narrow elliptic (1 genotype). Genotypes were divided into two categories namely, medium (32 genotypes) and large (43 genotypes) on the basis of grain size of mark of germ. On the basis of grain colour of vitreous albumen genotypes were characterized into three groups viz., grayed yellow (59 genotypes), grayed orange (10 genotypes) and grayed purple (6 genotypes). Genotypes could be divided into two groups namely, lusterous (44 genotypes) and non lusterous (31 genotypes) on the basis of grain luster. ) These characterization are in accordance with those Ram et al., (1998), Nagaraja et al., (2000), Selvaraju et al., (2000), Thangavel et al., (2005), Elangovan (2006) and Missihoun et al., (2015).

From the present investigation it may be concluded that the morphological DUS descriptors can be effectively used for identification and grouping of varieties and varieties satisfying the DUS criteria for these morphological descriptors could be registered under the PPV and FR Act for obtaining Plant breeders and Farmers' rights. However, morphological descriptors alone may not be sufficient for DUS criteria.

\section{References}

Dossou-Aminon I., Yeyinou Loko L., Adjatin A., Eben-Ezer B.K., Dansi A., Rakshit S., Cisse N., Patil J.V., Agbangla C., Ambaliou S., Akpovi A., and Akpagana K. (2015). Genetic divergence in northern Benin sorghum (Sorghum bicolor L. Moench) landraces as revealed by agromorphological traits and selection of candidate genotypes. Scientific World J.. .DOI 10.1155/916476.

Elangovan, M. (2006). Characterization and evaluation of exotic sorghum germplasm collections. Int. J. Agril. Sci. 2(1): 231234.

Elangovan, M., Prabhakar and Reddy, D.C.S. (2007). Characterization and evaluation of sorghum [Sorghum bicolor (L.) Moench] germplasm from Karnataka, India. Karnataka J. Agril. Sci. 20(4): 840842.

Joshi, D.C., Shrotria, P.K., Singh, R. and Chawla, H.S., (2009). Morphological characterization of forage sorghum [Sorghum bicolor (L.) Moench] varieties for DUS testing. Ind. J. Genet. Pl. Breeding. 69(4): 383-393.

Kannababu, N., Rakshit S., Audilakshmi, S., Tonapi, V. A., Patil, J. V., Dhandapani, A., Reddy, D. C. S., Venugopal, K., Swarnalatha, M., Balakrishna, G., Raghunath, K. and Subhakar, V., (2013). Genetic variability among Indian rainy season sorghum cultivars revealed by morpho-agronomic traits. Indian J. of Genetics and Plant Breeding. 73: 110-115

Kolberg, H. (1999). Morphological variability in sorghum (Sorghum bicolor (L.) Moench subsp. bicolor) accession from Namibia. Pl. Genet. Res. Newsletter. 117: 51-54.

Nabi, C.G., Muhammad, R. and Ghulam, A. (2006). Comparison of some advanced lines of \{Sorghum bicolor (L.) Monech\} 
for green fodder/dry matter yields and morpho-economic parameters. J. Agril. Res. Lahore. 44(3): 191-196.

Missihoun, A. A., Sagbadja, H.A., Ezin, V., Sedah, P., Dagba, R. A., Ahanhanzo, C., Agbangla, C. (2015) Phenotypic variability and racial classification of landraces of sorghum (Sorghum bicolor (L.) Moench) collected in the Northwestern Benin. Int. J. Agri. and Agri. R. 7(4): 23-35

Nagaraja, G.S., Varier, A., Singh, U. and Sharma, S.P. (2000). Characterization of inbreds and hybrids of sorghum \{Sorghum bicolor (L.) Moench\} by seed and seedling morphology and electrophoresis of seed proteins and isoenzymes. Pl. Var. and Seeds. 13(1): 17-29.

Pahuja, S.K., Grewal, R.P.S., Singh, N., Singh, P., Jindal, Y. and Pundir, S.R. (2002). Evaluation of forage sorghum hybrids for yield and morphological traits. Int. Sorghum and Millets Newsletter. 43: 4245.

PPV and FRA, (2007a). http://www.plant authority.gov.in/pdf/contents.pdf

Raghuvanshi, S., Dharanendra Swamy, Mahadevakumar, S. and Singh, O.P. (2014). DUS descriptor of seventeen forage cultivars of Sorghum [Sorghum bicolour (L.) Moench], Glob. J. bio-sci and biotech. 3: 100-108.

Ram, C., Punia, R.C., Grewal, R.P.S. and Lodhi, G.P. (1998). Characterization of sorghum cultivars for tannic acid. Forage Res. 24(2): 125-126.

Reddy, B.V.S., Sharma, H.C., Thakur, R.P. and Ramesh, S. (2006). Special issue: Characterization of

ICRISAT- bred Sorghum hybrid parents (set I). Int. Sorghum and Millets Newsletter. 47:
138.

Reddy, D.C.S., Audilakshmi, S. and Seetharama, N. (2009). Genetic variability and divergence for DUS testing traits in sorghum (Sorghum bicolor). Ind. J. Agril. Sci. 79(4): 286290.

Reddy, R.N., Mohan, S.M., Madhusudhana, R., Umakanth, A.V., Satish, K. and Srinivas, G., (2008). Inheritance of morphological characters in sorghum. J. SAT Agril. Res. 6: $1-3$.

Sangwan, V.P., Chauhan, P. and Ram, C. (2005). Varietal identification of forage sorghum through morphological characters. Seed Res. 33(1): 117-118

Selvaraju, P. and Sivasubramaniam, K. (2000). Identification keys for sorghum varieties. Madras Agril. J. 87: 10-12.

Shehzad T., and Okuno K., (2014). Diversity assessment of sorghum germplasm and its utilization in genetic analysis of quantitative traits-A review. AJCS. 8(6): 937-944.

Thangavel, P., Bhatati, A., Natarajan, N. and Evera, T. (2005). Varietal grouping in sorghum by seed and seedling morphology and response to chemical testing. Karnataka J. Agril. Sci. 18(3): 664-672.

Umakanth, A.V., Madhusudhana, R., Swarnlata, K. and Rana, B.S. (2002). Genetic diversity studies in sorghum. Int. Sorghum and Millets Newsletter. 43: 3133.

Upadhyaya, H. D., Yadav, D., Dronavalli, N., Gowda, CLL., and Singh S., (2010). Mini core germplasm collections for infusing genetic diversity in plant breeding programs. Electr. J. Plant Breed. 1(4): 1294-130.

\section{How to cite this article:}

Deepak Raj Prajapati, S.K. Pahuja, N.K. Verma and Shalu Chaudhary. 2018. Morphological Characterization of Sorghum [Sorghum bicolor (L.) Moench] Germplasm for DUS Traits. Int.J.Curr.Microbiol.App.Sci. 7(02): 2058-2071. doi: https://doi.org/10.20546/ijcmas.2018.702.246 